\title{
Correction to: Comparison of cervical sagittal parameters among patients with neck pain and healthy controls: a comparative cross-sectional study
}

\author{
Morteza Faghih Jouibari ${ }^{1}$. Jean Charles Le Huec ${ }^{2}$. Mohammad Hosein Ranjbar Hameghavandi ${ }^{3}$. \\ Navid Moghadam ${ }^{3} \cdot$ Farzin Farahbakhsh $^{1,3} \cdot$ Masoud Khadivi $^{1} \cdot$ Mohsen Rostami $^{4}(\mathbb{1}) \cdot$ Ramin Kordi $^{3}$
}

Published online: 12 October 2019

(c) Springer-Verlag GmbH Germany, part of Springer Nature 2019

\section{Correction to: European Spine Journal https://doi.org/10.1007/s00586-019-06117-8}

Unfortunately, the affiliation of the second author (Jean Charles Le Huec) was incorrectly published in the original publication.

The complete correct affiliation is given below.

Polyclinique Bordeaux Nord Aquitaine, Spine Unit, University Bordeaux, 33000 Bordeaux, France.

Publisher's Note Springer Nature remains neutral with regard to jurisdictional claims in published maps and institutional affiliations.

The original article can be found online at https://doi.org/10.1007/ s00586-019-06117-8.

Mohsen Rostami

rostami.moh@gmail.com

1 Department of Neurosurgery, Shariati Hospital, Tehran University of Medical Sciences, Tehran, Iran

2 Polyclinique Bordeaux Nord Aquitaine, Spine Unit, University Bordeaux, 33000 Bordeaux, France

3 Sports Medicine Research Center, Neuroscience Institute, Tehran University of Medical Sciences, Tehran, Iran

4 Brain and Spinal Cord Injuries Research Center, Neuroscience Institute, Imam Hospital, Tehran University of Medical Sciences, Keshavarz Boulevard Street, Tehran, Iran 